\title{
THE ANTI-NATURALISTIC LEGACY OF MENGER AND MISES
}

\begin{abstract}
The article focuses on the anti-naturalism of Menger and Mises. It presents a methodological approach formulated by both scholars as stemming from epistemological anti-naturalism and demonstrating similarities to social phenomenology. The article also discusses the development of the antinaturalistic perspective on the basis of Hayek's conception of sensory order. The latter allowed addressing the problem of validity of methodological dualism and established a sound foundation for the methodological approach of the Austrian School of Economics.
\end{abstract}

Keywords: Carl Menger, Ludwig von Mises, epistemological antinaturalism, social phenomenology, sensory order, limits of cognition

Carl Menger (1840-1921) and Ludwig von Mises (1881-1973) were among the most prominent economic thinkers and key figures of the Austrian School of Economics. They played a central role in establishing and shaping the methodological foundations of the latter. Their perception of economic phenomena as rooted in the creative and entrepreneurial activity of human beings reflects the strong anti-naturalist perspective adopted by representatives of the Austrian School.

The aim of this article is to examine the anti-naturalist legacy of Menger and Mises. The paper is divided into four sections. The first part briefly presents methodological assumptions of Menger and Mises. It is followed by analysis of epistemological anti-naturalism embedded in these assumptions. Section III discusses development of the anti-naturalistic approach in the context of Friedrich Hayek's reflection regarding human cognition. Section IV concludes. 


\section{Methodology of Menger and Mises}

Menger is considered a founder of the Austrian School of Economics. In 1871 he published Principles of Economics (Grundsätze der Volkswirtschaftslehre) in which he presented the foundations of his economic theory. His ideas regarding research of economic phenomena formed the methodological core of the Austrian School. The importance of Menger's work led Hayek to ascertainment that as for this school "its fundamental ideas belong fully and wholly to Carl Menger" (Hayek, 1981, p. 12).

Menger based his considerations regarding economy on methodological individualism, recognising the human as a basic agential factor of social phenomena. In this sense his viewpoint revolved around the action process in which the human tends to achieve his aims and therefore to satisfy his needs. Simultaneously, because the choice of aims is based on the agent's personal appraisal of how he satisfies his needs, this perspective led Menger to embrace a subjectivist point of view. This allowed the Austrian economist to develop a subjective theory of value, which consequently led him to erect the foundations of the subjective conception of human action. The latter implies that not only the human attributes subjective values to particular goods, but also that these values reflect the agent's perception of capability of these goods to satisfy his needs. In this sense Menger argued in favour of the subjective character of human cognition: "Value is thus the importance that individual goods or quantities of goods attain for us because we are conscious of being dependent on command of them for the satisfaction of our needs" (Menger, [1871] 2007, p. 115). This means that a person acts according to subjective valuation of his wants, therefore attaching meaning to his actions (Milonakis \& Fine, 2009, p. 103). Simultaneously the Austrian economist equipped the human being with the ability to grasp the meaning of people's actions. This, in turn, allows explaining studied phenomena by unveiling the exact reason of their existence. In this sense his approach to comprehending social processes and events presents a resemblance to the concept of understanding (Verstehen) developed later by Max Webber (Hayek, 1973, p. 8; Lachmann, 1977, p. 49). Simultaneously, Menger rejected implementation of mathematical methods in social sciences, as incoherent with causal explanation. Due to the subjective nature of meanings, understanding social phenomena differs from the way scholars study and explain phenomena in natural sciences. As Menger wrote in his letter to Léon Walras "[w]e do not simply study quantitative relationships but also the nature [or essence] of economic phenomena. How can we attain to the knowledge of this latter (e.g., the nature of value, rent, profit, the division of labor, 
bimetallism, etc.) by mathematical methods?" (Hutchison, 1973, p. 17).

According to Jesus Huerta de Soto (2010a, p. 39) the subjective conception of human action is Menger's most significant contribution. Not only does it incorporate the subjective theory of value, but also leads to the conclusion that the law of marginal utility, which Menger discovered in parallel with William Jevons and Walras, is a mere consequence of the former. In this sense, Menger's marginalism not only differs from one presented by other economists but also, contrarily to some scholars (Hutchison, 1953, p. 141), does not constitute the main aspect of Austrian's work (Jaffé, 1976; Machaj, 2015). Instead it is methodological subjectivism that forms the core element of Menger's approach to economics.

Mises is often considered the most important representative of the Austrian School of Economics (Hülsmann, 2007). As a successor of Menger's subjectivism, he successfully implemented this approach in new areas of economics, like the theory of money, credit, and economic cycle, or research in the impossibility of socialism. He also further developed the methodological foundations of the Austrian School. Mises, similarly to Menger, recognised the human being as the protagonist of all social events. As a result he based his research upon the concept of human action, understood as any purposeful behaviour. This general perspective meant that, although focusing mainly on economic phenomena, he recognised economics only as one of many fields of study in the more general branch of science of human action, known as praxeology. ${ }^{1}$ It also led Mises to distinguish the character of his field of study from neoclassical economics. As he wrote: "What distinguishes the Austrian School and will lend it everlasting fame is its doctrine of economic action, in contrast to one of economic equilibrium or inaction (Mises, 1978, p. 36).

Mises's approach, similarly to Menger's, is strictly connected with methodological subjectivism. Purposeful human action results from the mental activity of choosing aims according to values the actor attaches to these aims. However, these values result from subjective assessment of the actor's satisfaction from realisation of these aims. Mises also developed the Mengerian approach in terms of comprehending social phenomena. With his praxeological perspective that places human action in the centre of all social phenomena, he managed to elaborate and generalize the subjective conception of human action. Adopting the idea of subjective valuation he extended it beyond the area of economy, consequently identifying it with the source of human activity and perceiving subjectivism as the methodological foundation for a study of any social phenomena. In this sense he managed to fully express and emphasise the idea of subjectivism suggested 
by Menger. Together with adoption of a Weberian understanding of social phenomena, this led him to consider the idea of subjective valuation as "a specific application of a more general verstehen or understandingoriented approach to the human sciences, that is, the influential tradition of German social thought that is associated with the names Wilhelm Dilthey, Heinrich Rickert, J.G. Droysen, Max Weber, and Alfred Schütz" (Boettke, et. al, 2004, p. 329).

Subjective perception driving human action is strictly linked with human genuine creativity. The latter reflects the fact that because of the subjective character of meaning an individual attaches to various elements of reality, he can attain a novel perspective allowing him to discover and perceive new opportunities to achieve his goals. For Mises this fact was a necessary implication of the concept of human action. It constitutes the entrepreneurial feature of human beings, understood as a capacity to "recognize opportunities for profit which appear in environment and to act accordingly to take advantage of them" (Huerta de Soto, 2010b, p. 8).

Mises not only greatly contributed to the development of the subjective perspective present in the methodology of the Austrian School, but also successfully applied it in various areas of research. This caused Hayek to conclude that with reference to subjectivism:

This is a development which has probably been carried out most consistently by L. v. Mises and I believe that most peculiarities of his views which at first strike many readers as strange and unacceptable are due to the fact that in that consistent development of the subjectivist approach he has for a long time moved ahead of his contemporaries. Probably all the characteristic features of his theories, from his theory of money (...) from this central position (Hayek, 1952, p. 209-210).

Implementation of the above approach allowed Mises to create, among others, the theory of the impossibility of socialism (Mises, 1981). He argued that the faultiness of the idea of a centrally planned economy has its source in inability to recognise the role of the subjective character of human valuation:

The illusion that a rational order of economic management is possible in a society based on public ownership of the means of production owed its origin to the value theory of the classical economists and its tenacity to the failure of many modern economists to think through consistently to its ultimate conclusions the fundamental theorem of the subjectivist theory. Thus the socialist utopias were generated and preserved by the shortcomings of those schools of thought which the Marxians reject as 'an ideological disguise of the selfish class interest of the exploiting bourgeoisie.' In truth it was the errors of these schools that made the socialist ideas thrive (Mises, 1998, p. 207). 
Mises pointed out that formation of prices on the market results from interpersonal exchange of goods, which takes place according to subjective judgment of the value of these goods set by individual agents. Meanwhile, coercion embedded in socialism, and to a lesser extent in an interventionist system, limits agents' ability to realise such voluntary exchange. Therefore it hinders or completely prevents the emergence of market prices. This, in turn, deprives the governing body of information necessary for economic calculation, understood as an assessment of the value effects of alternative decisions.

\section{The anti-naturalistic Foundation of Methodology of Menger and Mises}

The approach of the Austrian School of Economics, formulated and developed by Menger and Mises, is based on epistemological anti-naturalism. The latter refers to a position according to which there exist social phenomena which cannot be explained by the scientific method of investigation applied to the natural world. ${ }^{2}$ In this sense it implies the distinctness of cognition in social science from cognition in natural science, emphasising the role of understanding and interpretation of social phenomena. Simultaneously it rejects objectivism typical for natural science.

Regarding the Austrian School, its epistemological antinaturalism forms the cornerstone of the Austrian methodological perspective - the subjective conception of human action. The latter implies that human action, and therefore any social phenomena, is caused by subjective valuation of aims and means. In other words it depends on meaning which a given individual attaches subjectively to various elements of perceived reality. Therefore perception of human action and its aims as the ultimate given reflects subjective mental processes. In this sense the process by which meanings are formulated in reference to stimulus perceived by the cognitive system cannot be fully described by the methods of natural science.

Concrete value judgments and definite human actions are not open to further analysis. We may fairly assume or believe that they are absolutely dependent upon and conditioned by their causes. But as long as we do not know how external facts - physical and physiological - produce in a human mind definite thoughts and volitions resulting in concrete acts, we have to face an insurmountable methodological dualism. In the present state of our knowledge the fundamental statements of (...) monism (...) are mere metaphysical postulates devoid of any scientific foundation and both meaningless and useless for scientific research (Mises, 1998, p. 17-18). 
This means that environment influences human action only through meanings which a given individual attributes to elements of this environment. In this sense meaning "is the way in which man reacts to the conditions of his environment" (Mises, 1998, p. 96). ${ }^{3}$ Additionally it is human action which reflects meanings. Therefore it is interpretation of human actions that provides an explanation of social processes. This, in turn, leads to adoption of the concept of understanding (Verstehen) as the proper approach in social science.

The above approach means that the starting point for studying social processes are the mental states of people. As Hayek wrote:

In fact, most of the objects of social or human action are not 'objective facts' in the special narrow sense in which this term is used by Science and contrasted to 'opinions', and they cannot at all be defined in physical terms. So far as human actions are concerned things are what the acting people think they are (Hayek, 1955, p. 26-27).

This however does not imply relativism. Society is not a set of fully independent, atomised beings. Perception of social phenomena is based on meanings and interpretative patterns that are common to agents creating a given social reality. In this sense society is an intersubjective construct formed by people's interpretations.

The existence of a common hermeneutical perspective stems from the fact that people belong to the same species, which determines the similarity of their cognitive structures. According to Mises "we are all human beings and can therefore use this knowledge to apply it to others of the same species" (Mises, 1957, xvii). Additionally, intersubjectivism reflects the fact that as "social animals" people share a social environment, which translates into similar categories and interpretative patterns. This allows various actors to interpret the same social processes in a similar manner. In this sense it establishes understanding between agents, understood as a convergence of meanings, which allows an actor to form expectations about the reaction of others to his actions. This, in turn, provides people with an opportunity to mutually adjust their activities, leading to the emergence of patterns of behaviour and non-chaotic interactions. Therefore "[t]he prototype of all social relations is an intersubjective connection of motives" (Schütz, 1960, p. 215). In this sense subjectivism refers to understanding social phenomena as based on the experience of belonging to a community.

The above approach implies that the methodological subjectivism of the Austrian Schoool is not synonymous with arbitrariness (Zanotti, 2007, p. 116). In this sense the former does not necessarily lead to the prob- 
lem of subjective-objective dichotomy. A praxeological approach, based on the common structure of human minds, means that human beings make decisions using a framework of rational choice, which is common to all people regardless of their knowledge (Boettke, 1998). This knowledge differs among individuals, as it is the cultural and historical context which shapes the ideas and beliefs of individuals, leading to differences in interpretation of observed reality. However, this does not imply a lack of common elements within human mental structure (Tooby \& Cosmides, 1992). Therefore, although it is an individual human being who interprets the world he perceives, he does so with categories and meanings similar to others.

The antinaturalistic approach of the Austrian School demonstrates a similarity to that of social phenomenology. The latter links the Weberian approach of individualism and subjectivism with the phenomenology of Edmund Husserl. The former implies that understanding of social phenomena should refer to the concept of intentionality, which is present in any human action. Because these phenomena result from the actions of individuals, subjective intentions which are behind these actions are the central element of research in terms of causal explanation:

I cannot understand a social thing without reducing it to the human activity which has created it and, beyond it, without referring this human activity tothe motives out of which it springs. I do not understand a tool without knowing the purpose for which it was designed, a sign or a symbol without knowing what it stands for, an institution if I am unfamiliar with its goals, a work of art if I neglect the intentions of the artist which it realizes (Schütz, 1960, p. 211).

Phenomenology, in turn, postulates the rejection of an assumption of an objective and constant character of social reality. Instead this reality is the effect of the activity of people belonging to it. This means that objects of which it consists represent meanings attributed to human actions. Therefore, as a result of these actions it is not placed outside of individual actors, but embedded in meanings formed by the human mind. Such a world does not consist of objective beings, but of phenomena. It is a world of everyday life consisting of subjective impressions of human beings - the "Life-world" (Lebenswelt). As a result it should be observed and studied in the way it is experienced. Simultaneously, because people share cognitive patterns and consequently meanings, the Life-world represents a form of intersubjective construction. As a "grand theatre of objects variously arranged in space and time relative to perceiving subjects, is already-always there, and is the 'ground' for all shared human experience" (Husserl, 1970, p. 142). Similarly 
to the Austrian School, social phenomenology places understanding upon the foundation of the experience of being in a community. This means that although it is the individual person who attaches meaning to elements of the world he perceives, it does not imply that this process takes place in isolation and independently from other people. Instead it is embedded in social interactions and therefore commonly experienced. In this sense it is the intersubjective character of the world which determines the subjectivity of human perception, not the other way around.

\section{Anti-naturalism and the limits of human cognition}

The antinaturalism of Menger and Mises is reflected in the subjective conception of human action, according to which meanings shaping human actions have a subjective character. The Austrian School of Economics uses this approach to indicate the impossibility of aggregation of information necessary to economic calculation in a centrally planned economy, thereby constituting a foundation of its liberal economic and political conceptions. This however raises a question about the validity of the antinaturalistic perspective. On what basis does antinaturalism presuppose that there are social phenomena which cannot be explained with scientific methods? What difficulties related to the use of the scientific method in social science justify the implementation of essentially different methods of investigation than those present in natural science?

The above question defines one of the most fundamental disputes in philosophy of science between naturalism and antinaturalism (monism and dualism), regarding whether social science should use the same methods of investigation as natural science. This problem stems from the general appreciation of scientific knowledge present in the latter and resulting from the tremendous progress which various disciplines of natural science have experienced due to the precision and testability of scientific method. Contrarily, formation of testable laws and predictions in social science presents substantial difficulties and drawbacks. ${ }^{4}$ However, problems which implement scientific method to explain social phenomena do not necessarily constitute a sound foundation for methodological dualism. Formation of predictions face difficulties also in "hard science". This refers to quasi-deterministic systems of quantum physics as well as to deterministic phenomena of high complexity. In case of the latter this complexity precludes possession of com-

plete knowledge about the initial state of these phenomena. What is more, solving problems which they address may require computing power exceed- 
ing available resources. As a result a particular problem can be intracable, which means that it cannot be solved due to limits in time and computing power. However this restriction has a relative character and poses no absolute barrier in terms of the capabilities of human cognition. Therefore it does not imply that the problem is in principle unsolvable.

The above approach to solvability of natural phenomena can be extrapolated to social processes. In this sense difficulties with using scientific methods to solve problems in social science stem from intractability, but not necessarily from the insolvability, of these problems. Therefore forming predictions in social science depends on precision of available data and use of adequate mathematical tools. According to Klaus Mainzer (2007), similarly to complex physical processes, social phenomena can be described using non-linear models, which take into account dependences between factors shaping these phenomena. Among others, this provides an argument against the antinaturalism of Menger and Mises. The praxeological perspective of the Austrian School implies that, by leading to human actions, mental states constitute the causal factor of social processes. Therefore the explanation of social processes should take place in terms of human mental states. This led Mises to the conclusion that "as long as we do not know how external facts - physical and physiological - produce in a human mind definite thoughts and volitions resulting in concrete acts, we have to face an insurmountable methodological dualism" (1998, p. 17). However, due to the distinction between intractable and insolvable problems, the implication formed by Mises seems to be unfounded. The inability to fully explain mental states with methods of natural science does not mean that this problem is insolvable, but rather that it is intractable. Consequently, although implementation of the scientific method does not allow formulating exact laws and precise predictions regarding this problem, this does not necessarily imply rejection of this method and adaptation of subjectivism. Instead it may provide an approximation of scientific explanation. What is more, in his argument Mises considered explanation as formed in terms of mental states. In this sense he did not address the form of naturalistic approach for which explanation of social processes takes place in respect to phenomena outside of human mental states. Although recognition of mental states as a causal factor may seem intuitively correct, it does not necessarily exclude recognition of laws based on other aspects of social reality.

The above considerations raise a question about the validity of methodological dualism. One scholar who recognised the problem this situation raises for the methodological approach of the Austrian School of Economics 
was Hayek. In his studies he covered a wide range of topics going beyond reflection on economic and social phenomena. In particular he studied the issue of cognition and its limits (Hayek, 1952). To describe the structure of human cognition Hayek distinguished between neuronal and sensory (phenomenal) orders. The former refers to a system of neurons and synapses together with processes of forming and transmitting impulses within this system. The sensory order, in turn, refers to all sensory qualities. It creates sensations of the cognising subject through a classification of stimuli from the external world and perceived by the neuronal order. This means that the relation between these orders is isomorphic, but only when considered as a whole. Therefore "the sensory (or other mental) qualities are not in some manner originally attached to, or an original attribute of, the individual physiological impulses, but that the whole of these qualities is determined by the system of connexions by which the impulses can be transmitted from neuron to neuron" (Hayek, 1952, p. 53).

Such construction of the cognitive system means that human perception depends on a classification of stimuli by sensory order. However this classification is not permanent and static. The neuronal order changes through the life of a human being due to its interaction with the external environment, which leads to changes in the structure of connections between neurons. As a result a reaction to a given situation (stimulus) may change in time.

Hayek's conception of the sensory order implies that this order is not isomorphic with the order of the external world. Classification of stimuluses changes dynamically together with any experience gained by an individual. This means that similarities in genotype and environmental conditions reflect in similarities between the classification apparatuses of various people. However simultaneously, as it is individual experience which shapes an agent's sensory order, it translates into the unique character of this order and, consequently, the subjective character of an agent's knowledge. In this sense Hayek's concept provides the foundation for methodological subjectivism in terms of the human cognitive system.

Hayek's idea of sensory order developed from his reflections regarding economic and political processes. It served to challenge the problem of methodological dualism and to establish a sound foundation for the antinaturalistic approach of the Austrian School. It led the Austrian scholar to recognise that, apart from practical limitations reflecting the existence of intractable problems, there are also absolute limitations on human cognition. They refer to the inherent and impassable barriers for cognitive processes. Their existence Hayek based on his conception of cognition as a classification process. He argues that the "apparatus of classification must possess 
a structure of higher degree of complexity than is possessed by the object which it classifies" (Hayek, 1952, p. 185). ${ }^{5}$ This necessity stems from the fact that objects belonging to different classes present different sets of attributes according to which the classification takes place. Otherwise these objects would not differ. This means that the number of classes that can be formed for a given classification reflects the number of combinations of classes of attributes to which these objects can be assigned. Consequently, the apparatus of classification does not provide enough classes to classify an object of higher degree of complexity than the apparatus. Together with recognition of the human mind as such an apparatus this indicates the existence of limits on cognition. In particular, it precludes a complete explanation of the mind itself. This is because it would require a cognitive system more complex than the mind. However even if such a system is possible, its implementation would require explanation of the system itself. Otherwise, it leads to contradiction with the fact that explanation must refer to human cognition and therefore must be based on the human mind. This, in turn, indicates the necessity of an apparatus of even higher degree of complexity, eventually leading to an infinite sequence of consecutive cognitive apparatuses, each of which is necessary to explain a preceding one.

Lack of a complete explanation of the human mind does not mean that no explanation is possible. Knowledge about studied phenomenon is gradable and it depends on the level of detail of the classification system formed by a cognitive apparatus. Therefore the more complex the explained structure is, the less accurate the knowledge about this structure. Simultaneously cognitive limitations stemming from Hayek's concept are absolute and impassable, as they do not depend on time or particular cognitive capabilities.

Recognition of the relation between explanation and complexity of investigated phenomena has an impact on the problem of methodological dualism. In the case of social phenomena, being a result of human actions means that they are dependent on the activity of the human cognitive apparatus. This links their complexity with the complexity of the apparatus. Simultaneously, however, this dependence means that explanation of such phenomena requires explanation of the cognitive system. Consequently, the degree of detail of explanation depends on the degree of influence of the human mind upon investigated phenomena (Gorazda, 2013, p. 101-102). This causes the level of detail of explanation to differ between objects of study and consequently leads to rejection of epistemological naturalism. Natural phenomena present a high level of independence from the sensory order, allowing "hard science" to formulate explanations based on exact laws. In contrast, social phenomena comprise human activity, which makes them 
closely related to human cognition, causing explanation in social science to have a more general character than in natural sciences. It also causes the former to be incapable of forming precise predictions.

\section{Conclusions}

Menger and Mises created the methodological foundations of the Austrian School of Economics. They based their approach on the subjective conception of human action, which has its source in epistemological antinaturalism. For both Austrian scholars social science does not study the deterministic elements of external reality, but purposefully acting human beings. Therefore, the facts of this science are not physical properties of objects, but meanings people assign to these objects. As a result the perspective of the Austrian School presents a strong resemblance to the approach of social phenomenology.

The antinaturalistic legacy of Menger and Mises was later developed by Hayek, who recognised and addressed the problem of the validity of methodological dualism. With his conception of sensory order he managed to indicate the existence of absolute limits of human cognition. This, in turn, allowed him to defend the position according to which the transition of stimuli perceived by a cognitive system into meanings cannot be explained by the methods of natural science.

\section{N O T E S}

${ }^{1}$ Creation of the concept of praxeology is commonly attributed to Alfred Espinas (Alexandre, 2000, p. 7).

2 Explanation here means the formulation of laws applicable to a given case and allowing logical transition from explanandum to explanans. Natural word refers to reality perceived intersubjectively using sensory apparatus.

3 The inability of the language of natural science to fully grasp human action leads also to the distinction between human action and the automatic and passive reaction of an organism to external conditions. The latter is deterministic and can be described in terms of biological or physical processes, therefore using methods of natural science. In contrast, the former requires an irreducible process of assigning meaning to these conditions. In this sense human action is indeterministic from the perspective of natural science and provides for the existence of genuine choice characterising a human being. The latter can be interpreted as human will: "For the term will means nothing else than man's faculty to choose between different states of affairs, to prefer one, to set aside the other, and to behave according to the decision made in aiming at the chosen state and forsaking the other" (Mises, 1998, p. 13). 
4 This asymmetry leads to a phenomena which Philip Mirowski (1991) described as "physic envy". It manifests itself in a tendency of representatives of social science to pursue accuracy and ability to provide predictions typically present in the natural science, especially in physics. This strongly resonates with naturalism, as it embodies a belief that implementation of methods of "hard sciences" would provide "more" scientific results. What's more, this tendency is especially visible in the field of economics which, somehow ironically, Menger and Mises used as a basis for the development of their antinaturalistic approach.

${ }^{5}$ For Hayek the degree of complexity reflects "[t]he minimum number of elements of which an instance of the pattern must consist in order to exhibit all the characteristic attributes of the class of patterns in question" $(1967$, p. 25). This means that for a given object its degree of complexity is determined by the number of classes to which it may be assigned.

\section{R E F E R E N C E S}

Alexandre, V. (2000). Introduction. In V. Alexandre, \& W. Gasparski (Eds.), The Roots of Praxiology: French Action Theory from Bourdeau and Espinas to Present Days (pp. 7-20). New Brunswick: Transaction Publishers.

Boettke, P. J. (1998). Rational Choice and Human Agency in Economics and Sociology: Exploring the Weber-Austrian Connection. In H. Giersch (Ed.), Merits and Limits of Market (pp. 53-81). Berlin: Springer.

Boettke, P., Lavoie, D., \& Storr, V. H. (2004). The Subjectivist Methodology of Austrian Economics and Dewey's Theory of Inquiry. In E. Kahlil (Ed.), Dewey, Pragmatism and Economic Methodology (pp. 327-356). London: Routledge.

Gorazda, M. (2013). Granice Wyjaśnienia Naukowego. Część II. Zagadnienia Filozoficzne w Nauce, 52, 53-106.

Hayek, F. A. (1952). The Sensory Order. An Inquiry into the Foundations of Theoretical Psychology. London: Routledge \& Kegan Paul.

Hayek, F. A. (1955). The Counter Revolution of Science: Studies on the Abuse of Reason. New York: The Free Press of Glencoe.

Hayek, F. A. (1967). Studies in Philosophy, Politics and Economics. London: Routledge \& Kegan Paul.

Hayek, F. A. (1973). The Place of Menger's Grundsätze in the History of Economic Thought. In J. Hicks, \& W. Weber (Eds.). Carl Menger and the Austrian School of Economics (pp. 1-14). Oxford: Clarendon Press.

Hayek, Friedrich A. (1981), Introduction. In C. Menger, Principles of Economics (pp. 11-36). Auburn: Ludwig von Mises Institute.

Huerta de Soto, J. (2010a). The Austrian School: Market Order and Entrepreneurial Creativity. Cheltenham: Edward Elgar Publishing.

Huerta de Soto, J. (2010b). The Theory of Dynamic Efficiency. London: Routledge.

Husserl, E. (1970). The Crisis of the European Sciences and Transcendental Phenomenology: An Introduction to Phenomenological Philosophy. Evanston: Northwestern University Press. 
Hutchison, T. (1953). A Review of Economic Doctrines 1870-1929. Oxford: Clarendon Press.

Hutchison, T. (1973). Some Themes from Investigations into Method. In J. Hicks, \& W. Weber (Eds.), Carl Menger and the Austrian School of Economics (pp. 15-37). Oxford: Clarendon Press.

Hülsmann, J. G. (2007). Mises: The Last Knight of Liberalism. Auburn: Ludwig von Mises Institute.

Jaffé, W. (1976). Menger, Jevons and Walras De-Homogenised. Economic Inquiry, $14(1), 511-524$.

Lachmann, L. (1977). The Significance of the Austrian School of Economic in the History of Ideas. In L. Lachmann, Capital, Expectations, and the Market Process: Essays on the Theory of the Market Economy (pp. 45-64). Kansas City: Sheed Andrews and McMeel, Inc.

Machaj, M., (2015). Marginal Unit vs. Marginal Unit - Some Additional Thoughts on the Differences between Menger, Jevons, and Walras. Ekonomia. Wrockaw Economic Review, 21(4), 9-16.

Mainzer, K. (2007). Thinking in Complexity. The Computational Dynamics of Matter, Mind, and Mankind. Berlin \& Heidelberg: Springer.

Menger, C. (1871) [2007]. Principles of Economics. Auburn: Ludwig von Mises Institute.

Milonakis, D., Fine, B. (2009). From Political Economy to Economics: Method, the social and the historical in the evolution of economic theory. London/New York: Routledge.

Mirowski, P. (1991). More Heat than Light: Economics as Social Physics, Physics as Nature's Economics. Cambridge: Cambridge University Press.

Mises, L. von (1957). Theory and History: An Interpretation of Social and Economic Evolution. New Haven: Yale University Press.

Mises, L. von (1978). Notes and Recollections. South Hollan: Libertarian Press.

Mises, L. von (1981). Socialism: An Economic and Sociological Analysis (3rd ed.) Indianapolis: Liberty Press.

Mises, L. von (1998). Human Action: A Treatise on Economics. Auburn: Ludwig von Mises Institute.

Schütz, A. (1960). The Social World and the Theory of Social Action. Social Research, 27, 203-221.

Tooby, J., \& Cosmides, L. (1992). The Psychological Foundations of Culture. In L. Cosmides, J. Tooby, \& J. H. Barkow, The Adapted Mind: Evolutionary Psychology and Generation of Culture (pp. 19-136). New York, Oxford: Oxford University Press.

Zanotti, G. J. (2007). Intersubjectivity, Subjectivism, Social Sciences, and the Austrian School of Economics. Journal of Markets 83 Morality, 10(1), 115-141. 